\title{
Post-growth Annealing of Cadmium Zinc Telluride Crystals for Room-Temperature Radiation Detectors
}

\author{
G. YANG,${ }^{1,4}$ A.E. BOLOTNIKOV ${ }^{1}$ P.M. FOCHUK,${ }^{1,2}$ Y. CUI,${ }^{1}$ \\ G. S. CAMARDA,${ }^{1}$ A. HOSSAIN,${ }^{1}$ K. H. KIM,${ }^{1}$ J. HORACE,${ }^{1,3}$ B. MCCALL,${ }^{1,3}$ \\ R. GUL, ${ }^{1}$ O.V. KOPACH, ${ }^{1,2}$ S.U. EGARIEVWE, ${ }^{1,3}$ and R.B. JAMES ${ }^{1}$ \\ 1.-Brookhaven National Laboratory, Upton, NY 11973, USA. 2.-Chernivtsi National \\ University, Chernivtsi, Ukraine. 3.-Alabama A\&M University, Huntsville, AL, USA. 4.- e-mail: \\ gyang@bnl.gov
}

We investigated the effects of post-growth annealing on cadmium zinc telluride crystals intended for use as room-temperature radiation detectors. Annealing under $\mathrm{Cd}$ vapor effectively eliminated Te inclusions. The material's resistivity was lowered, and loss of $\mathrm{Zn}$ component was observed. Annealing under $\mathrm{Cd}+\mathrm{Zn}$ vapors similarly removed Te inclusions. Furthermore, after exposure to the two vapors, we noted a change in the crystal surface morphology, i.e., formation of patterns of parallel lines. In contrast to annealing under $\mathrm{Cd}$ vapor alone, high resistivity was maintained after suitably controlling the $\mathrm{Cd}$ and $\mathrm{Zn}$ pressures.

Key words: CZT, post-growth annealing, Te inclusions, resistivity, surface morphology

\section{INTRODUCTION}

The II-VI compound semiconductor cadmium zinc telluride (CZT) is recognized as one of the leading materials for fabricating high-efficiency, high-resolution room-temperature x-ray and gamma-ray radiation detectors. ${ }^{1-3}$ Its unique properties include high average atomic number ensuring efficient radiation-atomic interaction, large bandgap offering high resistivity and low leakage current, high electron mobility-lifetime product, and availability of materials with large cross-sectional area and thickness. ${ }^{1}$ These merits fulfill the needs of a wealth of diverse applications, such as nuclear medical imaging, nonproliferation inspections, industrial monitoring, environmental safety and remediation, astronomical observations, and basic physics investigations. However, it is still a challenge to achieve good-quality CZT crystals at low cost. As-grown CZT crystals usually include different material defects that lower the yield of the ingots, and increase the expense of production. For example, Te inclusions are one of most common

(Received November 11, 2011; accepted February 12, 2012; published online March 17, 2012) defects in as-grown CZT. ${ }^{1,2}$ Their presence at high densities lowers the efficiency of charge collection and degrades the detector performance. ${ }^{3}$ Therefore, suitable approaches are being sought to eliminate Te inclusions in CZT crystals. Many efforts have been made to modify the conditions during growth to avoid their formation. However, CZT crystals for radiation detectors usually are grown under Te-rich conditions to assure their high resistivity; this poses the problem of supplementing properly with extra Cd to suppress sublimation of Cd from CZT during growth. As another choice, post-growth annealing offers more controllable, reproducible ways for reducing Te inclusions. In this work, we conducted post-growth annealing of CZT crystals at different temperatures and under controlled atmospheres. We compared the changes in CZT crystals annealed under Cd vapor only with those annealed under combinations of $\mathrm{Cd}$ and $\mathrm{Zn}$ vapors. Here, we report the effects of these different annealing conditions on their properties.

\section{EXPERIMENTAL PROCEDURES}

In this study, the CZT crystals were grown by the high-pressure Bridgman method and the 
conventional Bridgman method. All the as-grown CZT crystals had resistivity above $10^{8} \Omega \mathrm{cm}$. The thicknesses of the samples varied from $2 \mathrm{~mm}$ to $3.5 \mathrm{~mm}$. We polished the crystals' surfaces sequentially with suspensions of alumina particles of $5 \mu \mathrm{m}$, $1 \mu \mathrm{m}$, and $0.1 \mu \mathrm{m}$. Then, we removed their damaged surface layers with a solution of bromine in methanol. For the annealing experiments, the CZT crystals and the annealing source $(\mathrm{Cd}$, or $\mathrm{Cd}+\mathrm{Zn})$ were put into quartz ampoules that then were sealed under vacuum of $10^{-5}$ Torr. These sealed ampoules were placed in an annealing furnace with predetermined temperature profiles, so ensuring that the annealing source provided a suitable overpressure around CZT crystals.

The effects of annealing were evaluated by infrared (IR) transmission microscopy, currentvoltage $(I-V)$ curves, and low-temperature photoluminescence (PL) spectroscopy. Te inclusions are opaque to IR light, while the matrix of the CZT crystals is transparent. Hence, the IR transmission images can reflect changes of Te inclusions before and after annealing. For the $I-V$ measurements, we placed planar Au electrodes on the crystals' top and bottom surfaces by electroless chemical deposition, and then measured the $I-V$ curves with a Keithley 237 high-voltage source-measure unit. The change of resistivity prior and after annealing, calculated from $I-V$ results, can be ascribed to the properties of bulk crystals, since the side-surface treatment is the same for the as-grown and annealed samples. For our PL measurements, the CZT samples were attached to a cold copper finger within a continuousflow helium cryostat keeping the sample temperature at $\sim 4.2 \mathrm{~K}$. We employed a laser operating at $488 \mathrm{~nm}$ to excite the CZT, and the PL signal was collected by an iHR 550 tri-grating monochromator controlled by an external computer.

\section{RESULTS AND DISCUSSION}

Figure 1 shows representative IR images of a CZT crystal annealed at $670^{\circ} \mathrm{C}$ for $50 \mathrm{~h}$ in Cd overpressure. A temperature gradient of about $30^{\circ} \mathrm{C} / \mathrm{cm}$ was applied across the sample. Clearly, all the small Te inclusions ( $1 \mu \mathrm{m}$ to $5 \mu \mathrm{m}$ in this sample) were removed after annealing. The large Te inclusions $(15 \mu \mathrm{m}$ to $30 \mu \mathrm{m})$ migrated towards the hightemperature end; some of them became elongated into narrow bands during their migration, leaving small black spots behind. We ascribed the elimination of the small Te inclusions to diffusion: Cd diffuses into the CZT and forms the compound CdTe with them; alternatively, Te atoms from these inclusions may diffuse out and react with Cd interstitials within the surface of the crystal or $\mathrm{Cd}$ atoms in the nearsurface region. It would take much longer to totally remove the large $\mathrm{Te}$ inclusions if the diffusion mechanism of Cd or Te atoms only is operative. However, a temperature gradient would apply a driving force for migration of such Te inclusions. When the annealing temperature is higher than the melting point of Te, i.e., $449^{\circ} \mathrm{C}$, the Te inclusions will transform into Te-rich liquid droplets. At the high-temperature end of Te inclusions, CZT dissolves into these Te-rich liquid droplets; in contrast, the CZT becomes solidified at the cold end of the droplets. Consequently, the Te inclusions will move towards the high-temperature end. Vydyanath et al. ${ }^{4}$ first proposed such a migratory mechanism during their annealing work to improve the quality of $\mathrm{CdTe}$ and $\mathrm{Cd}_{0.96} \mathrm{Zn}_{0.04} \mathrm{Te}$ as a substrate for $\mathrm{HgCdTe}$ epilayer. We note that, compared with large-size Te inclusions, small ones are relatively difficult to migrate even under the same temperature gradient. The possible reason can be ascribed to the higher surface tension of the small $\mathrm{Te}$

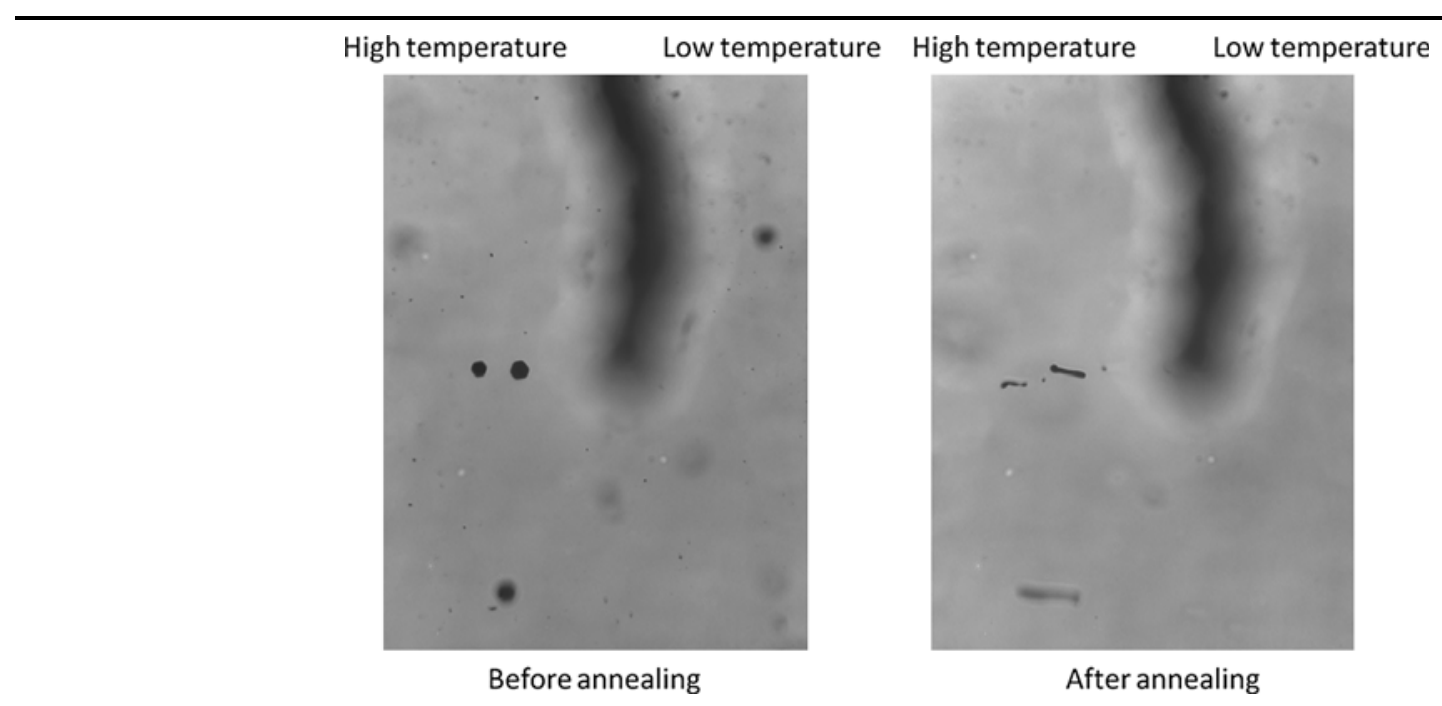

Fig. 1. Representative IR images of as-grown and annealed CZT crystal, showing the change of Te inclusions (the $\mathrm{CZT}$ was annealed at $670^{\circ} \mathrm{C}$ for $50 \mathrm{~h}$ in Cd overpressure). The area is $0.66 \mathrm{~mm} \times 0.90 \mathrm{~mm}$. 
inclusions; also, it is possible that the temperature difference across them might be insufficient to drive such a process. We noticed that, after the migration of some large Te inclusions, small black spots were left behind. Further, it was often observed that voids exist inside Te inclusions. ${ }^{5}$ Such voids might have originated from the strong stress field around the Te inclusions, because the thermal expansion coefficient of $\mathrm{Te}$ is considerably higher than that of CZT, or by coalescence of Cd vacancies at the Te-rich secondary phase. During the migration of these large Te inclusions, the voids cannot move with the main portion of the inclusions, so leaving behind small spots that scatter the IR light.

High resistivity is one of the prerequisites for CZT material used for radiation detection; it helps to reduce the leakage current and, therefore, lowers the system noise. Unfortunately, the resistivity of CZT declined after annealing in $\mathrm{Cd}$ vapor, even though the Te inclusions effectively were eliminated. In fact, the resistivity was reduced by five orders of magnitude after annealing at $670^{\circ} \mathrm{C}$ for $50 \mathrm{~h}$, as shown by the $I-V$ curves in Fig. 2 . Such a change turns the semi-insulating CZT into a semi-conducting material, and no energy spectra were observed in a detector fabricated from the CZT annealed only in $\mathrm{Cd}$. The compensation between the deep-level Te antisites, the Cd interstitials, and the Cd vacancies is considered responsible for the high resistivity of CZT. ${ }^{6,7}$ This compensation could be lost due to extra $\mathrm{Cd}$ interstitials introduced during annealing in $\mathrm{Cd}$ vapor, thereby shifting the Fermi level toward the bottom of the conduction band or the top of the valence band. Furthermore, we measured the lowtemperature PL spectrum of as-grown and annealed CZT (Fig. 3). It is well known that the exciton peak position serves as an indicator of the bandgap in CZT. ${ }^{8,9}$ Since this bandgap is enlarged with increasing $\mathrm{Zn}$ concentration, 8,9 the red-shift of the exciton peak clearly indicates that the $\mathrm{Zn}$ concentration is less after annealing in Cd vapor. This signifies that we cannot ignore the loss of $\mathrm{Zn}$ component when devising the approach to annealing CZT.
Consequently, we annealed CZT under both Cd vapor and $\mathrm{Zn}$ vapor to avoid loss of $\mathrm{Zn}$ during the process. During annealing, the CZT was kept at $750^{\circ} \mathrm{C}$ for $12 \mathrm{~h}$ and the temperatures of $\mathrm{Cd}$ and
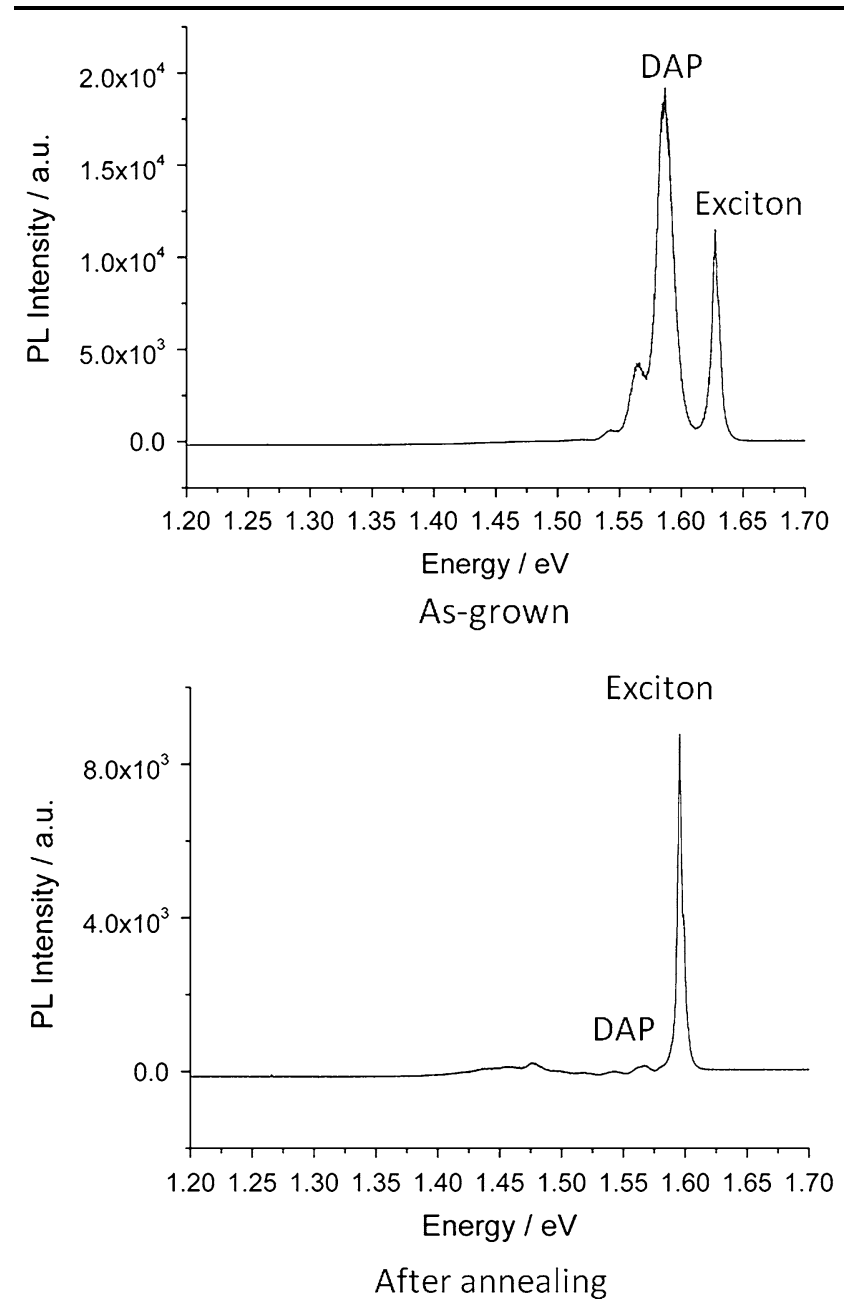

Fig. 3. Low-temperature PL spectrum of as-grown and Cd-vapor annealed CZT (donor-acceptor pair, DAP). A red-shift of exciton peak was observed (from $1.63 \mathrm{eV}$ to $1.60 \mathrm{eV}$ ). The PL measurements were taken at $4.2 \mathrm{~K}$.
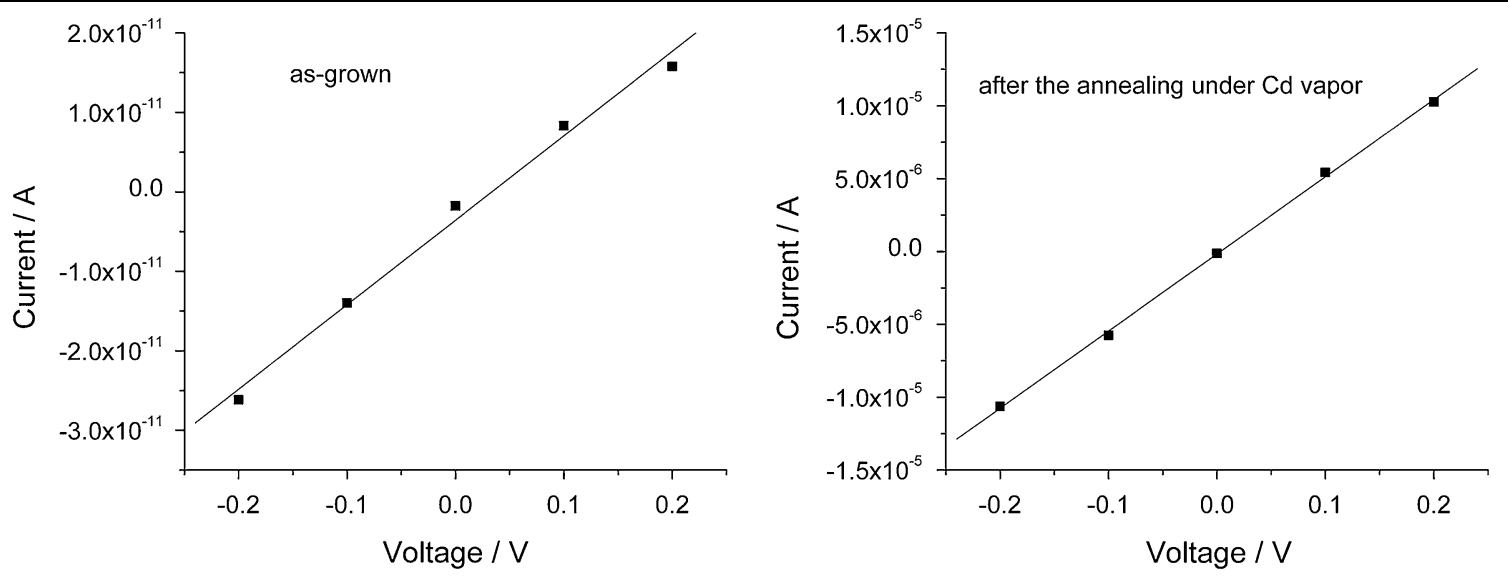

Fig. 2. $I-V$ curves of CZT after the annealing at $670^{\circ} \mathrm{C}$ for $50 \mathrm{~h}$ in Cd overpressure (dimensions of the sample are $7.0 \mathrm{~mm} \times 7.0 \mathrm{~mm} \times 4.5 \mathrm{~mm}$ ). The resistivity was lowered by five orders of magnitude after annealing. 


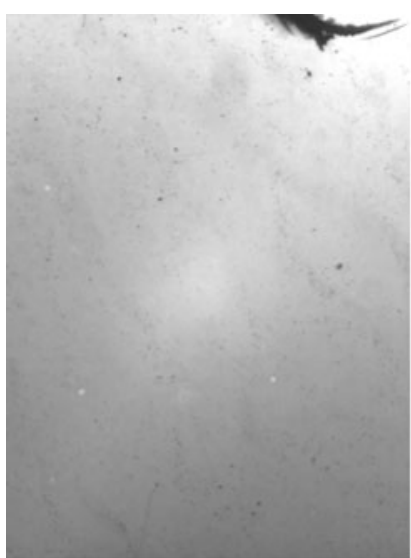

As-grown

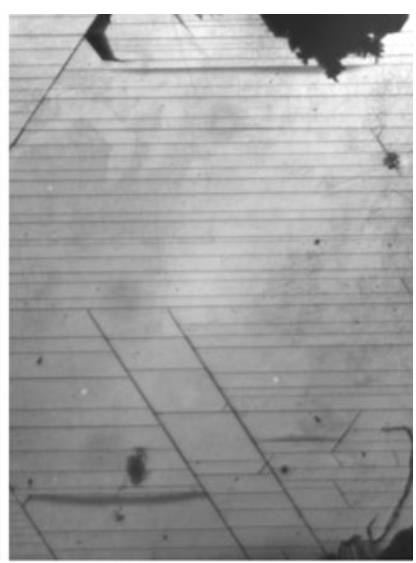

After annealing
Fig. 4. Surface morphology of as-grown CZT and annealed $\left(750^{\circ} \mathrm{C}\right.$ under $\mathrm{Cd}+\mathrm{Zn}$ vapor) $\mathrm{CZT}$. New line patterns were formed on the surfaces of CZT during the annealing.

$\mathrm{Zn}$ sources were controlled at $720^{\circ} \mathrm{C}$ and $820^{\circ} \mathrm{C}$ separately. Figure 4 shows the surface morphology of as-grown CZT and annealed (under $\mathrm{Cd}+\mathrm{Zn}$ vapor) CZT. As is apparent, some new patterns of lines formed on the surfaces of CZT during this annealing that did not appear after annealing in $\mathrm{Cd}$ vapor alone. It should be noted that these patterns are always present after annealing involving $\mathrm{Zn}$ overpressure. Most are parallel, and they resemble newly generated "twin bands." Jones et al. ${ }^{10}$ reported that a ternary compound, $\mathrm{Zn}_{x} \mathrm{Cd}_{1-x} \mathrm{Te}$ $(x=0.8)$, forms on the surface of CdTe when the mass of $\mathrm{Zn}$ placed in the ampoule exceeds $2 \mathrm{mg}$. Possibly, this situation is applicable to our experiments. This newly formed compound, $\mathrm{Zn}_{x} \mathrm{Cd}_{1-x} \mathrm{Te}$ $(x=0.8)$ is brittle, and readily fractures to produce ductile slips due to the differential stresses between this surface layer and the CZT matrix. ${ }^{11}$

To clarify whether the involvement of Zn affects the elimination of Te inclusions in CZT, we compared the change of Te inclusions before and after annealing under $\mathrm{Cd}$ and $\mathrm{Zn}$ vapor, as shown in Fig. 5. We found that all the Te inclusions were eliminated effectively by annealing under $\mathrm{Cd}$ and $\mathrm{Zn}$ vapor, which is similar to that for annealing in $\mathrm{Cd}$ vapor alone.

More importantly, we measured the $I-V$ characteristics of CZT after annealing under $\mathrm{Cd}$ and $\mathrm{Zn}$ vapor (Fig. 6). Clearly, the resistivity of CZT was maintained at a relatively high level of $10^{9} \Omega \mathrm{cm}$ after this annealing process. In our opinion, in-diffusion of $\mathrm{Zn}$ possibly limits the introduction of extra Cd interstitials, so helping to maintain pinning of the Fermi level and, thus, yielding high resistivity.

\section{CONCLUSIONS}

We investigated the effects of post-growth annealing on CZT crystals intended for use in roomtemperature radiation detectors. Annealing under $\mathrm{Cd}$ vapor effectively reduced the density of $\mathrm{Te}$

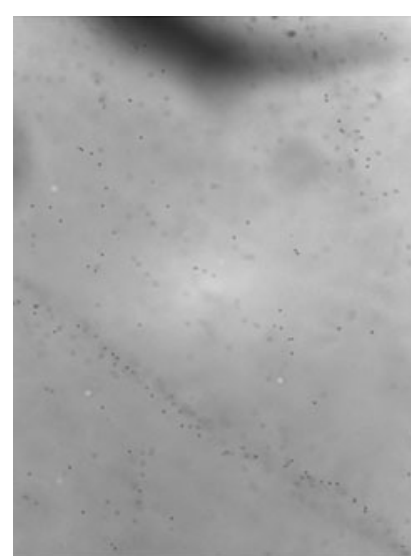

As-grown

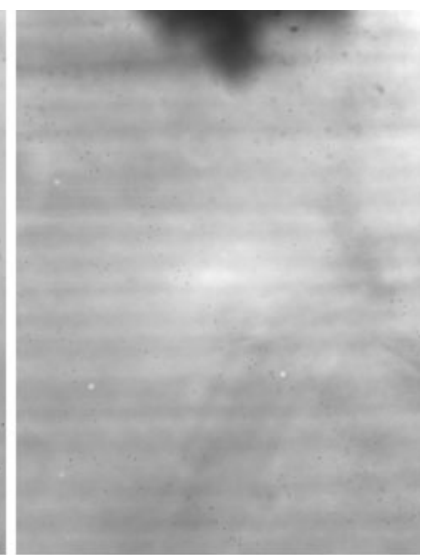

After annealing
Fig. 5. IR images of as-grown and annealed $\left(750^{\circ} \mathrm{C}\right.$ under $\mathrm{Cd}+\mathrm{Zn}$ vapor) CZT crystal, showing the reduction of Te inclusions. The area is $0.66 \mathrm{~mm} \times 0.90 \mathrm{~mm}$.

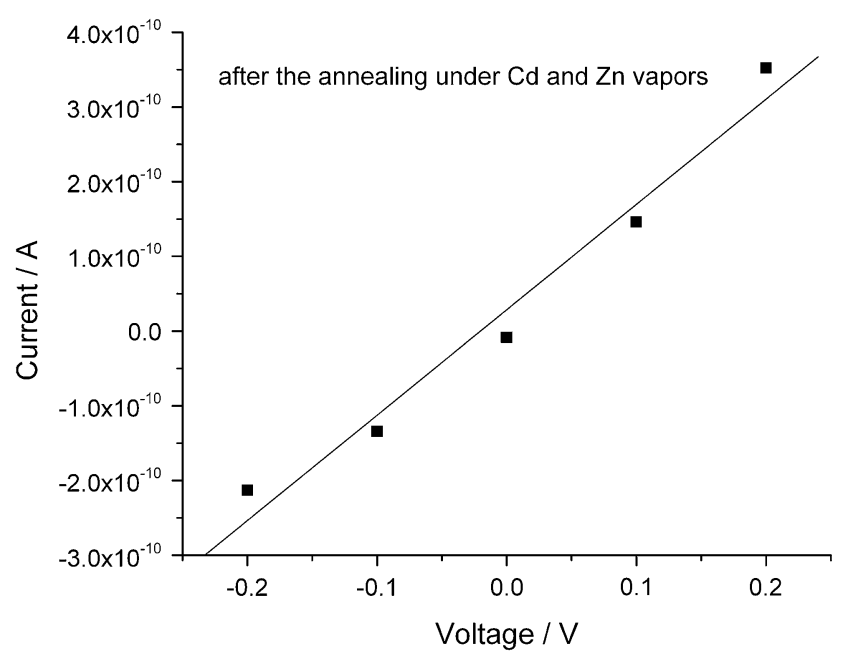

Fig. 6. $I-V$ curves of $\mathrm{CZT}$ after annealing at $750^{\circ} \mathrm{C}$ under $\mathrm{Cd}$ and $\mathrm{Zn}$ vapor (dimensions of the sample are $5.0 \mathrm{~mm} \times 5.0 \mathrm{~mm} \times 2.3 \mathrm{~mm}$ ). The resistivity was maintained at a level of $10^{9} \Omega \mathrm{cm}$ after annealing.

inclusions. We suggest that the elimination of Te inclusions of different sizes involves two mechanisms, viz. a diffusion mechanism and a thermalmigration mechanism driven by a temperature gradient field. Annealing under Cd vapor lowered the resistivity of CZT, and loss of Zn component in the near-surface region was observed. Annealing under both $\mathrm{Cd}$ and $\mathrm{Zn}$ vapors had similar effects in removing Te inclusions as those found under $\mathrm{Cd}$ vapor only. Furthermore, we observed a change in the crystal surface morphology; i.e., new patterns of parallel lines formed after annealing under $\mathrm{Cd}$ and $\mathrm{Zn}$ vapor. We achieved high resistivity after suitably controlling the $\mathrm{Cd}$ and $\mathrm{Zn}$ pressures.

\section{ACKNOWLEDGMENTS}

This work was supported by US Department of Energy, Office of Nonproliferation and Verification Research and Development, NA-22. The manuscript 
has been authored by Brookhaven Science Associates, LLC under Contract No. DE-AC02-98CH1-886 with the US Department of Energy.

\section{REFERENCES}

1. R.B. James, T.E. Schlesinger, J.C. Lund, and M. Schieber, Semiconductors for Room Temperature Nuclear Detector Applications, Vol. 43 (New York: Academic, 1995), p. 334.

2. C. Szeles, S.A. Soldner, S. Vydrin, J. Graves, and D.S. Bale, IEEE Trans. Nucl. Sci. 54, 1350 (2007).

3. A.E. Bolotnikov, N. Abdul-Jabber, S. Babalola, G.S. Camarda, Y. Cui, A. Hossain, E. Jackson, H. Jackson, J. James, K.T. Kohman, A. Luryi, and R.B. James, IEEE Trans. Nucl. Sci. 55,2757 (2008).

4. H.R. Vydyanath, J. Ellsworth, J.J. Kennedy, B. Dean, C.J. Johnson, G.T. Neugebauer, J. Sepich, and P.-K. Liao, J. Vac. Sci. Technol. B 10, 1476 (1992).
5. J. Shen, D.K. Aidun, L. Regel, and W.R. Wilcox, J. Cryst. Growth 132, 250 (1993).

6. V. Babentsov, J. Franc, P. Hoschl, M. Fiederle, K.W. Benz, N.V. Sochinskii, E. Dieguez, and R.B. James, Cryst. Res. Technol. 44, 1054 (2009).

7. M. Fiederle, C. Eiche, M. Salk, R. Schwarz, K.W. Bens, W. Stadler, D.M. Hofmann, and B.K. Meyer, J. Appl. Phys. 84, 6689 (1998).

8. G. Yang, A.E. Bolotnikov, Y. Cui, G.S. Camarda, A. Hossain, K.H. Kim, R. Gul, and R.B. James, Appl. Phys. Lett. 98, 261901 (2011).

9. T.E. Schlesinger, J.E. Toney, H. Yoon, E.Y. Lee, B.A. Brunett, L. Franks, and R.B. James, Mater. Sci. Eng. Rep. 32,103 (2001).

10. E.D. Jones, J.C. Clark, J.B. Mullin, and A.W. Brinkman, J. Cryst. Growth 138, 274 (1994).

11. N. Aslam, E.D. Jones, T.C.Q. Noakes, J.B. Mullin, and A.F.W. Willoughby, J. Cryst. Growth 117, 249 (1992). 